\title{
Don't sweat it: Medical management of hyperhidrosis
}

\author{
Brendon M. Stiles, MD
}

\author{
From the Division of Thoracic Surgery, Weill Cornell Medicine, New York-Presbyterian Hospital, New York, NY. \\ Disclosures: Author has nothing to disclose with regard to commercial support. \\ Received for publication March 28, 2016; accepted for publication March 30, 2016; available ahead of print May \\ $11,2016$. \\ Address for reprints: Brendon M. Stiles, MD, Division of Thoracic Surgery, Weill Cornell Medicine, New York- \\ Presbyterian Hospital, 525 East 68th St, Suite M404, New York, NY 10065 (E-mail: brs9035@nyp.org). \\ J Thorac Cardiovasc Surg 2016;152:569 \\ 0022-5223/ $\$ 36.00$ \\ Copyright (c) 2016 by The American Association for Thoracic Surgery \\ http://dx.doi.org/10.1016/j.jtcvs.2016.03.069
}

It is somewhat unusual to encounter a report in which surgeons describe the presentation of a condition for which there is a surgical solution, but then go on to highlight the potential for avoiding surgery for that condition. That appears to be exactly what we have here in the article by Hynes and colleagues ${ }^{1}$ describing extended medical management of patients referred for surgery for hyperhidrosis. The authors describe a series of 381 patients who presented with primary hyperhidrosis or facial blushing who were all offered a trial of an oral anticholinergic (OA) before surgery. Of these, $77 \%$ had already received some form of medical therapy before surgical referral. The authors report that approximately $60 \%$ of the patients were satisfied with the symptom control achieved with the OA and thus elected to not undergo surgery. An initial presentation with palmar symptoms and/or facial blushing was a predictor of the desire to proceed to surgery. This is not surprising, given the social implications of sweating from these sites. Also not surprising was the finding that patients who had previous attempts at medical therapy also were more likely to proceed to surgery.

So what are we to take home from this article? A subjective answer likely exists, just as the descriptions of symptom control and "satisfaction" with medical therapy are themselves subjective concepts. Here the authors present no data on actual patient satisfaction, but instead use "not going to surgery" as indicative of satisfaction with medical therapy. As surgeons know, many factors are involved in a patient's decision to undergo elective surgery, including, among others, personal or physician bias, family preference, and information gleaned from social media. The mean duration of follow-up for the nonoperative group was only 304 days, so how many of these patients will be "satisfied" and stick to medical therapy for what can be a socially disabling condition remains to be seen. Nevertheless, I was impressed by the high proportion of patients

\section{Reference}

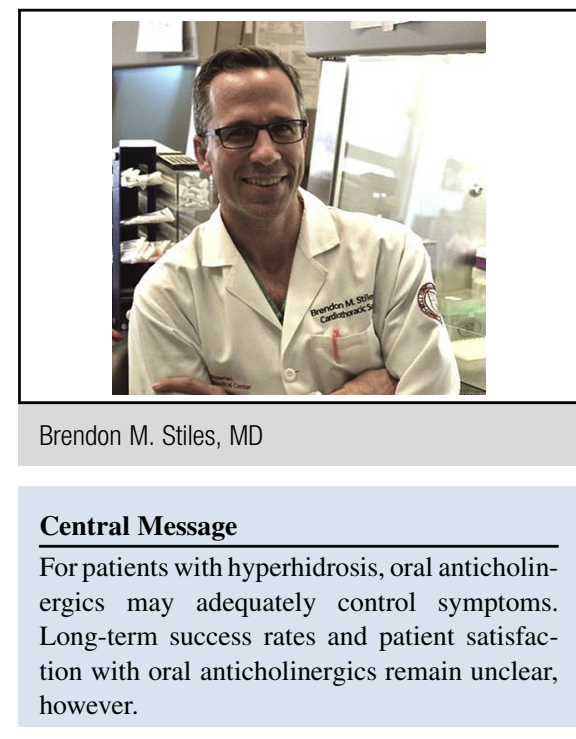

See Article page 565 .

that Hynes and associates did not take to the operating room. Their commitment to a deliberate, systematic approach to managing these patients should be applauded. It would seem that patients presenting with hyperhidrosis who have not had any previous courses of an OA should at least be offered glycopyrrolate or oxybutynin. This may be particularly true for patients with primary axillary or torso symptoms. Many of these patients may not ultimately need surgery, and there certainly seems to be little downside to delaying elective surgery.

We surgeons are by nature inclined to look for surgical solutions for our patients; however, we should always consider reasonable medical alternatives when they exist. As the authors make clear, we should not sweat a trial of OA for patients with hyperhidrosis. There appears to be little to lose. Nevertheless, we are beholden to follow these patients closely, given that long-term success rates and patient satisfaction with OA therapy remain unclear.

1. Hynes CF, Seevaratnam S, Gesuwan K, Margolis M, Marshall MB. The efficacy of oral anticholinergics for sympathetic overactivity in a thoracic surgery clinic. $J$ Thorac Cardiovasc Surg. 2016;152:565-8. 